\title{
(2) OPEN ACCESS \\ Using intermittent pulse oximetry to guide neonatal oxygen therapy in a low-resource context
}

\author{
Patrick James Berkeley Walker (1) ,,2 Ayobami Adebayo Bakare, \\ Adejumoke Idowu Ayede, ${ }^{3}$ Rosena Olubanke Oluwafemi, ${ }^{5}$ \\ Omolayo Adebukola Olubosede, ${ }^{6}$ Iyabo Victoria Olafimihan, ${ }^{7}$ Kenneth Tan $\left(10,{ }^{8,9}\right.$ \\ Trevor Duke ( , ${ }^{10,11}$ Adegoke Gbadegesin Falade, ${ }^{12,13}$ Hamish Graham (1) ${ }^{14}$
}

For numbered affiliations see end of article.

\section{Correspondence to} Dr Patrick James Berkeley Walker, Centre for International Child Health, Department of Paediatrics, The University of Melbourne, Parkville, VIC 3056, Australia;

patrickjbwalker@gmail.com

Received 27 May 2019 Revised 31 July 2019 Accepted 8 August 2019 Published Online First 28 August 2019

\section{Check for updates}

(c) Author(s) (or their employer(s)) 2020. Re-use permitted under CC BY. Published by BMJ.

To cite: Walker PJB, Bakare AA, Ayede Al, et al. Arch Dis Child Fetal Neonatal Ed 2020;105:F316-F321.

\section{ABSTRACT}

Objective To evaluate the effectiveness of intermittent pulse oximetry in guiding oxygen therapy in neonates in a low-resource setting.

Design and setting Prospective validation study at three hospitals in southwest Nigeria. We performed concealed continuous pulse oximetry on participants to evaluate intermittent $\mathrm{SpO}$ monitoring.

Patients We recruited all preterm or low birthweight neonates, and all term neonates who required oxygen therapy, who were admitted to the neonatal ward(s) of the study hospitals during the study period.

Main outcome measures Proportion of time preterm/ low birthweight neonates on oxygen spent within, above and below the target $\mathrm{SpO}_{2}$ range of $90 \%-95 \%$; and the proportion of time term neonates and neonates not on oxygen spent within and below the target range of 90\%-100\%.

Results Preterm/low birthweight neonates receiving oxygen therapy (group A) spent 15.7\% (95\% Cl 13.3 to 18.9 ) of time in the target $\mathrm{SpO}_{2}$ range of $90 \%-95 \%$. They spent $75.0 \%$ (63.6-81.1) of time above 95\%, and $2.7 \%(1.7-5.6)$ of time below $85 \%$. Term neonates and all neonates not receiving oxygen (group B) spent $97.3 \%$ (95\% Cl 96.4 to 98.6$)$ of time within the target range of $90 \%-100 \%$, and $0.9 \%(0.3-1.4)$ of time below $85 \%$. Guidelines recommended $\mathrm{SpO}_{2}$ monitoring 3 times per day for all patients, however neonates in groups $A$ and $B$ were monitored an average of 4.7 and 5.3 times per day, respectively.

Conclusions To better maintain $\mathrm{SpO}_{2}$ within the target range, preterm/low birthweight neonates on oxygen should have their $\mathrm{SpO}_{2}$ monitored more frequently than the current 4.7 times per day. In all other neonates, however, monitoring $\mathrm{SpO}_{2} 5.3$ times per day appears suitable.

\section{KUDOS SUMMARY}

This study sought to evaluate the effectiveness of intermittent pulse oximetry in guiding oxygen therapy in newborns in a low-resource setting. We conducted the study in three secondary-level hospitals in southwest Nigeria, where oxygen is available for use in newborns, but continuous monitoring of oxygen saturations is not available.

We found that preterm and low birthweight newborns receiving oxygen therapy, who have a narrow oxygen saturation target range of $90 \%-95 \%$, only spent $15.7 \%$ of time within the

\section{What is already known on this topic?}

- Oxygen is an essential medical therapy, but must be used judiciously in preterm and low birthweight neonates to avoid harm from retinopathy of prematurity (ROP) and bronchopulmonary dysplasia (BPD).

- This requires monitoring via pulse oximetry, to keep $\mathrm{SpO}_{2}$ within a target range of $90 \%-95 \%$.

- In many resource-poor settings, continuous pulse oximetry is not available, necessitating the use of intermittent monitoring to guide oxygen therapy.

\section{What this study adds?}

We found that preterm and low birthweight neonates spent only $15.7 \%$ of time within the target $\mathrm{SpO}_{2}$ range of $90 \%-95 \%$ while receiving oxygen, spending $75 \%$ of time above $95 \%$.

- Term neonates, however, spent almost all of their time within the target range.

- In preterm and low birthweight neonates receiving oxygen therapy, more frequent $\mathrm{SpO}_{2}$ monitoring could improve oxygen targeting and potentially prevent harm from ROP and BPD in resource-constrained hospitals.

target range. They spent $75 \%$ of time with saturations above $95 \%$, exposing them to potentially dangerous oxygen levels, which can lead to damage to their eyes and lungs. Term neonates and all neonates who were not receiving oxygen, however, spent almost all of their time $(97.3 \%)$ within their wider target range of 90\%-100\%.

These results show that to improve oxygen targeting, preterm and low birthweight newborns who are receiving oxygen should have their oxygen saturations more frequently monitored where this is possible. They also demonstrate a need to teach health workers in resource-constrained hospitals about the dangers of using too much oxygen in these patients, and how to respond to oxygen saturation readings above and below the target range.

\section{INTRODUCTION}

Oxygen is a life-saving medical therapy for sick newborns that has been used for over 100 years. ${ }^{1}$ 
When used in preterm (gestational age $<37$ weeks) and low birthweight (birth weight $<2000$ g) neonates, however, it carries significant risks-most notably retinopathy of prematurity (ROP) and bronchopulmonary dysplasia (BPD). ${ }^{2} 3$ Tight control of haemoglobin oxygen saturation $\left(\mathrm{SpO}_{2}\right)$ through use of pulse oximetry can prevent harm. ${ }^{24}$

The principal and most studied complication of hyperoxia in preterm neonates is ROP. In high-income countries (HICs), $\mathrm{ROP}$ is now uncommon due to effective $\mathrm{SpO}_{2}$ control in at-risk neonates. ${ }^{5}$ However, its prevalence is increasing in low-income and middle-income countries (LMICs) as neonatal preterm survival increases and oxygen is used excessively. This has been labelled the 'third epidemic' of ROP, and is thought to be responsible for 20000 new cases of blindness annually. ${ }^{67}$

While there continues to be some debate about the optimal $\mathrm{SpO}_{2}$ range for preterm and low birthweight neonates, it is thought to lie between approximately $90 \%$ and $95 \%,{ }^{24}$ with WHO recommending $88 \%-95 \% .{ }^{8}$ However, it is challenging to maintain $\mathrm{SpO}_{2}$ of preterm and low birthweight infants within these target ranges, and they often spend large proportions of time outside. ${ }^{9-11} \mathrm{SpO}_{2}$ targeting is particularly challenging in LMICs. Despite improvements in recent years, oxygen practices in many LMICs remain poor and pulse oximetry is rarely used to guide therapy. Hospital surveys consistently report very low availability of pulse oximeters for paediatric and neonatal use (typically $<10 \%$ ) and low staff awareness of how pulse oximetry should be used in children and newborns. ${ }^{12-16}$

In these settings, continuous $\mathrm{SpO}_{2}$ monitoring is often not possible and intermittent monitoring is increasingly used to guide oxygen therapy. However, it is unclear how effective it is in guiding oxygen therapy, particularly in neonates at risk of ROP and BPD.

This study seeks to evaluate the effectiveness of intermittent $\mathrm{SpO}_{2}$ monitoring in guiding oxygen therapy in neonates in a low-resource setting.

\section{METHODOLOGY \\ Study design}

We conducted a prospective validation study at three secondarylevel hospitals in southwest Nigeria, between June 2017 and March 2018. We evaluated the effectiveness of intermittent pulse oximetry monitoring (the current standard of care at all study hospitals) in guiding oxygen therapy in neonates by performing concealed continuous pulse oximetry on participants during routine care.

\section{Participants}

We recruited all preterm or low birthweight neonates, and all term neonates who required oxygen therapy, who were admitted to the neonatal ward(s) of the study hospitals during the study period. Inclusion and exclusion criteria are detailed in table 1.

\begin{tabular}{|c|c|}
\hline Inclusion criteria & Exclusion criteria \\
\hline \multirow{5}{*}{$\begin{array}{l}\text { All of: } \\
\text { 1. Admitted to nursery of study hospitals } \\
\text { during the study period. } \\
\text { 2. Preterm or low birth weight; or received } \\
\text { oxygen during admission. }\end{array}$} & Any of: \\
\hline & 1. Prescribed or required bubble \\
\hline & CPAP, high-flow oxygen (>2 L/ \\
\hline & $\min )$, or mechanical ventilation. \\
\hline & 2. Received palliative care. \\
\hline
\end{tabular}

CPAP, continuous positive airway pressure.

\section{Procedures}

Intermittent pulse oximetry using Lifebox pulse oximeters (Acare Technology, Taiwan) was a standard practice in all hospitals. We did not provide additional refresher training or reminders, as we intended to evaluate routine care. Staff had previously received training and supportive supervision on pulse oximetry and the oxygen protocol in November 2015. ${ }^{16}$ The oxygen protocol recommended using pulse oximetry for every neonate admitted to the nursery, and commencement of oxygen therapy if any $\mathrm{SpO}_{2}$ reading was $<90 \%$. Pulse oximeter probes were attached to neonates' hands or feet and nurses recorded the $\mathrm{SpO}_{2}$ reading in the patient's clinical observation chart after an adequate plethysmographic waveform was observed and the $\mathrm{SpO}_{2}$ reading was stable (typically within $1-2 \mathrm{~min}$ ). ${ }^{16}$ The protocol recommended checking the $\mathrm{SpO}_{2}$ on admission, within 15 min of any change in oxygen flow rate, and at least once per shift (3 times per day), or more frequently for neonates with severe respiratory distress or signs of deterioration. It recommended aiming for $\mathrm{SpO}_{2}$ 90\%-95\% for preterm or low birthweight neonates receiving oxygen therapy and $\mathrm{SpO}_{2} \geq 90 \%$ for other neonates. Monitoring data had shown consistently high use of pulse oximetry for neonates on admission (>90\%) and strong adoption into routine care practices. ${ }^{16}$

Data collection at each site was performed by a dedicated study nurse or PJBW, under the supervision of the project coordinator and co-principal investigators. We commenced concealed continuous $\mathrm{SpO}_{2}$ monitoring using Masimo Radical-7 CO-Oximeters (Masimo, Irvine, California, USA) after admission to the neonatal ward (or after commencement of oxygen therapy for term neonates), and continued it until 48 hours after oxygen was ceased, or to a maximum of 5 days (120 hours) for each patient. We concealed the visual display and disabled normal upper and lower limit alarms of the Masimo continuous oximeters so $\mathrm{SpO}_{2}$ readings could not be determined by staff or study investigators. However, to prevent avoidable harm from severe hypoxaemia occurring, we set a lower audible $\mathrm{SpO}_{2}$ alarm limit at $80 \%$, alerting nurses to potentially dangerously low $\mathrm{SpO}_{2}$ and prompting clinical review. We also ensured the plethysmographic waveform was visible to permit us to evaluate the accuracy of $\mathrm{SpO}_{2}$ readings. We collected data from the first study hospital (SH1) between 22 June 2017 and 31 July 2017, and the second and third study hospitals (SH2, SH3) between 29 November 2017 and 20 March 2018.

We downloaded $\mathrm{SpO}_{2}$ data using Profox oximetry software (Profox Associates, Coral Springs, Florida, USA), yielding .xlsx files, which we opened using Stata V.14.0 (StataCorp, College Station, Texas, USA) to enable cleaning and analysis.

\section{Outcomes}

The primary outcome for this study was the proportion of time preterm/low birthweight neonates spent in the target $\mathrm{SpO}_{2}$ range (90\%-95\%) while receiving oxygen therapy. Secondary outcomes were the proportion of time spent by 1) preterm/low birthweight neonates and 2) term neonates:

1. Below safe levels $\left(\mathrm{SpO}_{2}<85 \%\right)$;

2. Within safe range $\left(\mathrm{SpO}_{2} 85 \%-95 \%\right.$ for preterm/low birthweight neonates on oxygen; $85 \%-100 \%$ for term neonates, or any neonates not on oxygen);

3. Within target range $\left(\mathrm{SpO}_{2} 90 \%-95 \%\right.$ for preterm/low birthweight neonates on oxygen; $90 \%-100 \%$ for term neonates, or any neonates not on oxygen);

4. Above safe levels $\left(\mathrm{SpO}_{2}>95 \%\right.$ for preterm/low birthweight neonates on oxygen). 


\begin{tabular}{|c|c|c|}
\hline & $\begin{array}{l}\text { Preterm or LBW } \\
(n=50)\end{array}$ & $\begin{array}{l}\text { Term } \\
(n=36)\end{array}$ \\
\hline Sex & $24(48 \%)$ male & $22(61 \%)$ male \\
\hline $\begin{array}{l}\text { Hypoxaemic }\left(\mathrm{SpO}_{2}<90 \%\right) \text { at any time } \\
\text { during admission }\end{array}$ & $35(70 \%)$ & $26(72 \%)$ \\
\hline $\begin{array}{l}\text { Received oxygen at any time during } \\
\text { admission }\end{array}$ & $34(68 \%)$ & $36(100 \%)$ \\
\hline $\begin{array}{l}\text { Respiratory distress or tachypnoea (RR } \\
>60 \text { ) at admission }\end{array}$ & $15(30 \%)$ & $14(39 \%)$ \\
\hline $\begin{array}{l}\text { Received antibiotics on day } 1 \text { of } \\
\text { admission }\end{array}$ & $44(88 \%)$ & $30(83 \%)$ \\
\hline Discharged well & $27(54 \%)$ & $25(69 \%)$ \\
\hline Discharged against medical advice & $6(12 \%)$ & $4(11 \%)$ \\
\hline Died in hospital & $13(26 \%)$ & $5(14 \%)$ \\
\hline \multicolumn{3}{|c|}{ Admission diagnoses (including comorbidities) } \\
\hline Preterm & $\begin{aligned} 20 & (40 \%) \\
& 2(4 \%) \text { very } \\
& \text { preterm (GA } \\
& 28-32 \text { weeks) } \\
& 4(8 \%) \text { extremely } \\
& \text { preterm (GA } \\
& <28 \text { weeks) }\end{aligned}$ & $\mathrm{N} / \mathrm{A}$ \\
\hline Low birth weight & $\begin{array}{l}47(94 \%) \\
\quad 19(37 \%) \text { VLBW } \\
\quad 2(4 \%) \text { ELBW }\end{array}$ & N/A \\
\hline Apnoea & $22(44 \%)$ & $13(36 \%)$ \\
\hline Neonatal encephalopathy & $11(22 \%)$ & $27(75 \%)$ \\
\hline Suspected neonatal sepsis & $24(48 \%)$ & $15(42 \%)$ \\
\hline
\end{tabular}

BW, birth weight; extremely low birth weight (ELBW), BW <1000 g; GA, gestational age; low birth weight (LBW), BW <2000 g;N/A, not applicable; preterm, GA <37 weeks; RR, respiratory rate; very low birthweight (VLBW), BW 1000-1499g.

\section{Analysis}

We stratified participants into those with a target $\mathrm{SpO}_{2}$ range of 90\%-95\% (preterm/low birthweight neonates on oxygen) and those with a target range of $90 \%-100 \%$ (all other neonates). We then reported the primary and secondary outcomes as median values with 95\% CIs, as data were not normally distributed. We used Stata V.14.0 to conduct all data cleaning and analysis.

\section{Ethical aspects}

This study was conducted in accordance with the Australian National Statement on Ethical Conduct in Human Research. We

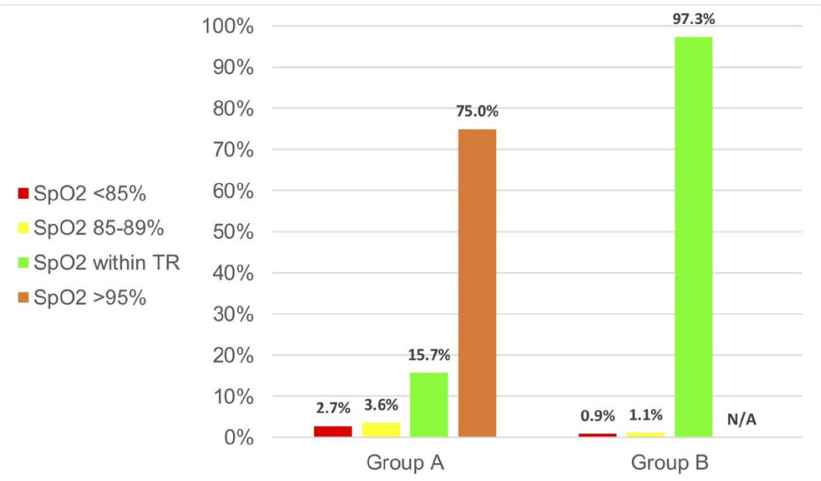

Group A: Preterm/low birthweight neonates on oxygen (target range 90-95\%; safe range 85 95\%); Group B: Term neonates, and any neonates not on oxygen (target range $90-100 \%$. safe range $85-100 \%)$. TR, target range $\left(\mathrm{SpO}_{2} 90-95 \%\right.$ for Group A; $90-100 \%$ for Group B).

Figure 1 Median proportion of time participants spent within and outside of target $\mathrm{SpO}_{2}$ ranges during the study period.
Table 3 Proportion of time participants spent within and outside target and safe $\mathrm{SpO}_{2}$ ranges during study period

\begin{tabular}{|c|c|c|}
\hline & $\begin{array}{l}\text { Group A (preterm/LBW } \\
\text { neonates on oxygen): } \\
\text { median }(95 \% \mathrm{Cl})\end{array}$ & $\begin{array}{l}\text { Group B (term neonates, } \\
\text { and any neonates not on } \\
\text { oxygen): median }(95 \% \mathrm{CI})\end{array}$ \\
\hline \multirow{4}{*}{$\begin{array}{l}\text { Below safe } \mathrm{SpO}_{2} \text { levels } \\
(<85 \%)\end{array}$} & $2.7 \%$ (1.7 to 5.6$)$ & $0.9 \%(0.3$ to 1.4$)$ \\
\hline & SH1: 3.3 (0.4 to 15.4$)$ & SH1: 0.3 (0.1 to 0.8 ) \\
\hline & SH2: 2.4 (1.3 to 8.3$)$ & SH2: 1.8 (0.3 to 24.3$)$ \\
\hline & SH3: 2.8 (2.5 to 7.6$)$ & SH3: 1.4 (0.9 to 2.9$)$ \\
\hline \multirow{4}{*}{$\begin{array}{l}\text { Within safe } \mathrm{SpO}_{2} \\
\text { range }(85 \%-95 \% \text { or } \\
85 \%-100 \%)\end{array}$} & $19.3 \%(16.2$ to 24.3$)$ & $99.1 \%$ (98.5 to 99.5$)$ \\
\hline & SH1: 16.8 (7.8 to 23.3 ) & SH1: 99.5 (99.1 to 99.7) \\
\hline & SH2: 24.5 (11.1 to 40.5$)$ & SH2: 98.2 (75.7 to 99.7$)$ \\
\hline & SH3: 19.2 (10.9 to 24.1$)$ & SH3: 98.6 (97.1 to 99.1$)$ \\
\hline \multirow{4}{*}{$\begin{array}{l}\text { Within target } \mathrm{SpO}_{2} \\
\text { range }(90 \%-95 \% \text { or } \\
90 \%-100 \%)\end{array}$} & $15.7 \%(13.3$ to 18.9$)$ & $97.3 \%(96.4$ to 98.7$)$ \\
\hline & SH1: 15.4 (6.7 to 18.7$)$ & SH1: 98.9 (97.0 to 99.2$)$ \\
\hline & SH2: 17.0 (10.2 to 24.4$)$ & SH2: 95.8 (62.8 to 98.3$)$ \\
\hline & SH3: 16.2 (9.5 to 20.5 ) & SH3: 96.1 (91.7 to 97.4) \\
\hline \multirow{4}{*}{$\begin{array}{l}\text { Above target } \mathrm{SpO}_{2} \\
\text { levels }(>95 \%)\end{array}$} & $75.0 \%(63.6$ to 81.1$)$ & \multirow[t]{4}{*}{$\mathrm{N} / \mathrm{A}$} \\
\hline & SH1: 78.5 (62.3 to 88.9$)$ & \\
\hline & SH2: 67.1 (40.0 to 81.3 ) & \\
\hline & SH3: 78.1 (68.4 to 86.4 ) & \\
\hline
\end{tabular}

LBW, low birth weight; N/A, not applicable; SH1/SH2/SH3, study hospitals 1, 2 and 3.

obtained written informed consent from a parent/guardian of all participants before enrolment in this study.

\section{RESULTS}

We recruited a total of 86 eligible neonates for this study: 41 from SH1, 26 from SH2 and 19 from SH3. Fifty-one participants were either preterm or low birth weight (19 at SH1, 17 at $\mathrm{SH} 2,15$ at $\mathrm{SH} 3)$, and 70 received oxygen during their admission (35 at SH1, 26 at SH2, 9 at SH3). Patient characteristics are detailed in table 2.

We monitored participants' $\mathrm{SpO}_{2}$ for a total of 5552 hours (231.3 patient-days). Of this, 4000 hours (166.7 days, $72.1 \%$ of total recording time) were for preterm/low birthweight neonates, including 1766 hours (73.6 days; $31.8 \%$ ) while receiving oxygen; 1551 hours (64.6 days, $27.9 \%$ ) were for term neonates.

\section{Frequency of monitoring}

During the study period, nurses recorded 1147 intermittent $\mathrm{SpO}_{2}$ readings on participants (mean 5.0 readings per patient per day) during routine care: 717 on preterm/low birthweight neonates (mean: 4.3 readings per patient per day; 4.7 while on oxygen; 4.2 while not on oxygen); 430 oximetry readings on term neonates (mean: 6.7 readings). Patients with a target $\mathrm{SpO}_{2}$ range of 90\%-95\% had their $\mathrm{SpO}_{2}$ monitored 4.7 times per day; those with a target range of $90 \%-100 \%$ were monitored 5.3 times per day (both mean values).

\section{Time within the target range}

Preterm and low birthweight neonates on oxygen spent only $15.7 \%$ (95\% CI 13.3 to 18.9 ) of time within the target $\mathrm{SpO}_{2}$ range of $90 \%-95 \%$. These neonates spent $75.0 \%$ of their time (63.6-81.1) with $\mathrm{SpO}_{2}>95 \%$, and $2.7 \%(1.7-5.6)$ of their time with $\mathrm{SpO}_{2}<85 \%$ (table 3, figure 1). Term neonates, and all neonates not on oxygen, however, spent 97.3\% (95\% CI 96.4 to 98.7$)$ of their time within the target range of 90\%-100\%, and only $0.9 \%(0.3-1.4)$ of their time with $\mathrm{SpO}_{2}$ below $85 \%$. Analysing both groups together, participants spent on average 
Table 4 Proportion of time participants spent within and outside target and safe ranges, comparing data from concealed continuous $\mathrm{SpO}_{2}$ monitoring and nurses' clinical records from intermittent monitoring

\begin{tabular}{|c|c|c|c|}
\hline & $\begin{array}{l}\text { All patients: } \\
\text { median }(95 \% \mathrm{CI})\end{array}$ & $\begin{array}{l}\text { Group A: median } \\
(95 \% \mathrm{CI})\end{array}$ & $\begin{array}{l}\text { Group B: median } \\
(95 \% \mathrm{CI})\end{array}$ \\
\hline \multicolumn{4}{|c|}{ As per continuous monitoring } \\
\hline Below safe range & $1.5 \%(1.0$ to 2.3$)$ & $2.7 \%(1.7$ to 5.6$)$ & $0.9 \%(0.3$ to 1.4$)$ \\
\hline Within safe range & $\begin{array}{l}96.2 \% \text { ( } 83.9 \text { to } \\
98.5)\end{array}$ & $19.3 \%$ (16.2 to 24.3$)$ & $\begin{array}{l}99.1 \% \text { (98.5 to } \\
99.5 \text { ) }\end{array}$ \\
\hline Within target range & $\begin{array}{l}92.5 \% \text { (78.5 to } \\
96.3)\end{array}$ & $15.7 \%(13.3$ to 18.9$)$ & $\begin{array}{l}97.3 \%(96.4 \text { to } \\
98.7)\end{array}$ \\
\hline Above target range & N/A & $75.0 \%$ (63.6 to 81.1$)$ & N/A \\
\hline \multicolumn{4}{|c|}{ As per nurses' record of intermittent monitoring } \\
\hline Below safe range & $7.3 \%$ & $16.0 \%$ & $3.6 \%$ \\
\hline Within safe range & $79.3 \%$ & $45.8 \%$ & $96.4 \%$ \\
\hline Within target range & $73.1 \%$ & $33.2 \%$ & $92.8 \%$ \\
\hline Above target range & N/A & $38.2 \%$ & $\mathrm{~N} / \mathrm{A}$ \\
\hline
\end{tabular}

Group A: preterm/low birthweight neonates on oxygen (target range 90\%-95\%; safe range $85 \%-95 \%$ ). Group B: term neonates, and any neonates not on oxygen (target range $90 \%-100 \%$; safe range $85 \%-100 \%$ ).

N/A, not applicable.

92.5\% (95\% CI 78.5 to 96.3 ) of time within the target range, and only $1.5 \%(1.0-2.3)$ of time with $\mathrm{SpO}_{2}<85 \%$.

Compared with concealed continuous $\mathrm{SpO}_{2}$ monitoring, nurses' oximetry records detected more time below the target range and less time above the target range (table 4). This was most evident in preterm infants on oxygen therapy.

\section{DISCUSSION}

Our findings suggest that current oximetry and oxygen practices in the study hospitals are appropriately maintaining $\mathrm{SpO}_{2}$ in the target range for term neonates, but are not adequately restricting oxygen therapy for preterm and low birthweight neonates. While term neonates spent $97 \%$ of time in the target range $(90 \%-100 \%)$, preterm/low birthweight neonates spent $15.7 \%$ of time in the target range $(90 \%-95 \%)$ while receiving oxygen. Neonates spent very little $(<2 \%)$ time below safe levels $(<85 \%)$, suggesting that oxygen therapy is being used effectively to prevent and treat hypoxia and its potentially lethal sequelae. ${ }^{18}$ However, preterm neonates on oxygen therapy spent $75 \%$ of time above the target range $(>95 \%)$. We did not measure ROP or BPD in our study, but the link between iatrogenic hyperoxia and these conditions is well-established ${ }^{4}{ }^{19-21}$ and excessive oxygen administration in the study hospitals therefore likely put these neonates at risk of harm.

Nurses' intermittent $\mathrm{SpO}_{2}$ recordings tended to overestimate the time spent below the target range and underestimate the time spent above the target range. This may indicate that nurses more actively look for (and act on) hypoxia than hyperoxia-a hypothesis supported by feedback from nurses at $\mathrm{SH} 1$ and previous studies. ${ }^{22} 23$ This has implications for auditing and designing oxygen systems in low-resource hospitals, where relying on recorded $\mathrm{SpO}_{2}$ readings may overestimate the time spent under target range, and underestimate the time spent above.

The Lifebox pulse oximeters used by nurses in this study were developed for low-resource settings by WHO and the World Federation of Societies for Anaesthesiologists, with rated accuracy of $\pm 2 \% .{ }^{24} 25$ They have been validated for use in children and neonates, and give comparable readings with leading commercial oximetry brands. ${ }^{2426}$
Existing evidence shows that even in resource-rich settings, it is difficult to control $\mathrm{SpO}_{2}$ accurately in preterm and low birthweight neonates. Data from large oxygen-targeting trials among extremely preterm neonates in HICs found that neonates spent $41 \%-67 \%$ of time outside the target range. ${ }^{9-11} 2728$ Oxygen targeting in our study was expectedly poorer than these studies, which were conducted in well-resourced settings using continuous pulse oximetry monitoring by dedicated neonatal intensive care nurses. Data from Kenya involving intermittent $\mathrm{SpO}_{2}$ monitoring found that in the first 24 hours of life, only $6.7 \%$ of preterm/low birthweight neonates remained consistently within the target $\mathrm{SpO}_{2}$ range, and more than half (53\%) had more $\mathrm{SpO}_{2}$ readings outside the target range than within. ${ }^{29}$

Common oxygen-related and oximetry-related challenges facing clinicians caring for neonates in resource-poor environments include:

1. Decreased capacity to detect hypoxic or hyperoxic episodes, which can increase the risk of $\mathrm{ROP}^{30}$;

2. Nurse:patient ratios as low as 1-2 nurses to $40-50$ neonates ${ }^{27}$;

3. Suboptimal staff education in oxygen administration to preterm/low birthweight neonates;

4. Tendency to favour hyperoxia over hypoxia. This observation is consistent with previous studies, and is thought to be related to the innocuous clinical presentation of hyperoxia compared with hypoxia. ${ }^{9112728}$

\section{Improving oximetry and oxygen practices in a low-resource environment}

Improved access to oxygen therapy globally has been associated with decreased neonatal mortality in many LMICs (particularly MICs) ${ }^{31}$ However, it has also fuelled a rise in the prevalence of ROP. ${ }^{632} 33$ Many hospitals now face challenges in the safe use of oxygen in preterm/low birthweight neonates. Our study shows that while pulse oximetry is an essential tool for promoting safe oxygen use, additional measures may need to be introduced for preterm and low birthweight neonates, who are most at risk of harm.

Potential avenues for improvement relate to the frequency of $\mathrm{SpO}_{2}$ monitoring, and adequate resource-provision and staffing of neonatal wards. The most financially feasible of these is likely frequency of $\mathrm{SpO}_{2}$ monitoring. As this study shows, checking $\mathrm{SpO}_{2}$ of neonates with a target range of $90 \%-100 \% 5.3$ times per day is sufficient to keep $\mathrm{SpO}_{2}$ within the desired range. However, in preterm/low birthweight neonates receiving oxygen, monitoring $\mathrm{SpO}_{2}$ more frequently than the current 4.7 times per day could lead to improved $\mathrm{SpO}_{2}$ control. Informal feedback from nurses at $\mathrm{SH} 1$ suggested that monitoring these neonates' $\mathrm{SpO}_{2}$ up to 12 times per day could be feasible, particularly as this change would only involve a minority of neonates. Structural changes such as designated high-dependency zones in neonatal wards with greater nursing resources could help achieve this. All changes to practice should, however, be determined by what is feasible and appropriate in each individual clinical setting.

Recently, automated closed-loop systems have been shown in high-income settings to enable superior $\mathrm{SpO}_{2}$ control in preterm/ low birthweight neonates. ${ }^{34-36}$ Further investigation is needed to ensure quality and safety of such systems, but application of this technology to simple oxygen systems in resource-constrained settings remains an exciting possibility.

Finally, many commonly used oxygen and oximetry guidelines, including those by WHO, do not make specific reference to how intermittent pulse oximetry should be used in neonates. ${ }^{8}$ Given 
the increasing use of this monitoring method in LMICs, there is future potential to include clearer guidance on its optimal use in neonates, particularly those born preterm or with low birth weight.

\section{Limitations}

This study has several limitations. First, the number of neonates enrolled in this study was low and involved only three hospitals. Furthermore, few participants were very/extremely preterm or very low/extremely low birth weight, the demographic most at risk of hyperoxic injury. Additional data in this patient group from low-income settings would be helpful to guide future oxygen practices. The study hospitals were also participating in an oxygen improvement project, and had already improved their oxygen practices substantially prior to this study. In the 2 years prior to this study, all three hospitals had adopted pulse oximetry into routine practice, and installed oxygen delivery systems that enabled them to more easily and accurately provide oxygen to patients (including 0-2 LPM flowmeters, nasal prongs, oxygen concentrators and reliable power supply). ${ }^{16}{ }^{17}$ Unpublished data show that the introduction of pulse oximetry did improve the quality of oxygen care in our study hospitals (personal correspondence, Dr Hamish Graham, January 2019). As such, these hospitals represent relatively good oxygen and pulse oximetry practices compared with most similarly resourced hospitals.

\section{CONCLUSIONS}

In this study, we found that in preterm and low birthweight neonates receiving oxygen therapy, monitoring $\mathrm{SpO}_{2}$ intermittently an average of 4.7 times per day using a simple decisionmaking algorithm was only sufficient to keep $\mathrm{SpO}_{2}$ within the target range of $90 \%-95 \%$ for a small proportion of time. However, the same procedure enabled nurses to adequately maintain all other neonates' $\mathrm{SpO}_{2}$ within a wider target range of 90\%-100\%. Preterm and low birthweight neonates on oxygen therapy spent $75 \%$ of time in hyperoxia, indicating a need to teach health workers to be alert to the dangers of hyperoxia and the safe upper threshold in these infants, and to enable them to monitor $\mathrm{SpO}_{2}$ frequently. Either intermittent or continuous pulse oximetry must be associated with adequate awareness and responses to avoid dangerous hypoxaemia or hyperoxia.

\footnotetext{
Author affiliations

${ }^{1}$ Centre for International Child Health, Department of Paediatrics, The University of Melbourne, Parkville, Victoria, Australia

${ }^{2}$ Medicine, Nursing \& Health Sciences, Monash University, Clayton, Victoria, Australia ${ }^{3}$ Department of Paediatrics, University of Ibadan, Ibadan, Nigeria

${ }^{4}$ University College Hospital Ibadan, Ibadan, Nigeria

${ }^{5}$ Department of Neonatology, Mother and Child Hospital, Akure, Nigeria

${ }^{6}$ Teaching Hospital Complex, University of Medical Sciences, Akure, Nigeria

${ }^{7}$ Department of Paediatrics, Sacred Heart Hospital, Abeokuta, Nigeria

${ }^{8}$ Department of Paediatrics, Monash University, Melbourne, Victoria, Australia

${ }^{9}$ Monash Newborn, Monash Children's Hospital, Melbourne, Victoria, Australia

${ }^{10}$ Intensive Care Unit and University of Melbourne Department of Paediatrics, Royal

Children's Hospital, Parkville, Victoria, Australia

${ }^{11}$ Department of Child Health, School of Medicine and Health Sciences, University of Papua New Guinea, Port Moresby, Papua New Guinea

${ }^{12}$ College of Medicine, University of Ibadan, Ibadan, Nigeria

${ }^{13}$ Department of Paediatrics, University College Hospital Ibadan, Ibadan, Nigeria

${ }^{14}$ Centre for International Child Health, University of Melbourne, Royal Children's

Hospital, Parkville, Victoria, Australia
}

Contributors PJBW, HG, TD, KT and AGF conceived and designed the study. PJBW, $\mathrm{HG}, \mathrm{AAB}, \mathrm{AIA}, \mathrm{ROO}, \mathrm{OAO}$, IVO and AGF participated in project implementation. PJW and $A A B$ were responsible for data collection. PJBW, $H G$ and $A A B$ contributed to data analysis and interpretation of results. PJBW drafted the manuscript. HG, TD and AGF provided substantial comments to the writing of the manuscript. All authors read and approved the final manuscript.
Funding The funders of the study include the Bill and Melinda Gates Foundation (financial support for the Nigeria Oxygen Implementation Project, in which this study is nested; OPP1123577), Masimo Corporation (provision of 10 Radical-7 COOximeters, probes, and one Windows laptop computer) and the Murdoch Children's Research Institute (\$A500 scholarship to support PJBW's involvement). All authors had full access to all the data in the study, and had final responsibility for the decision to submit for publication.

Disclaimer The funders played no role in study design, data collection, data analysis, data interpretation or writing of this report.

Competing interests None declared.

Patient consent for publication Not required.

Ethics approval This study obtained approval from the ethics committees at the University of Melbourne (Ethics ID 1748914), Monash University (Project Number 9398) and the University College Hospital/University of Ibadan (Ethics Committee Assigned Number UI/EC/16/0413).

Provenance and peer review Not commissioned; externally peer reviewed.

Data availability statement Data are available on reasonable request.

Open access This is an open access article distributed in accordance with the Creative Commons Attribution 4.0 Unported (CC BY 4.0) license, which permits others to copy, redistribute, remix, transform and build upon this work for any purpose, provided the original work is properly cited, a link to the licence is given, and indication of whether changes were made. See: https://creativecommons.org/ licenses/by/4.0/.

\section{ORCID iDs}

Patrick James Berkeley Walker http://orcid.org/0000-0002-0115-0516

Kenneth Tan http://orcid.org/0000-0002-1931-0549

Trevor Duke http://orcid.org/0000-0003-4637-1416

Hamish Graham http://orcid.org/0000-0003-2461-0463

\section{REFERENCES}

1 Duke T, Graham SM, Cherian MN, et al. Oxygen is an essential medicine: a call for international action. Int J Tuberc Lung Dis 2010;14:1362-8.

2 Askie LM, Darlow BA, Davis PG, et al. Effects of targeting lower versus higher arterial oxygen saturations on death or disability in preterm infants. Cochrane Database Syst Rev 2017;368.

3 Stenson BJ. Oxygen saturation targets for extremely preterm infants after the NeOProM trials. Neonatology 2016;109:352-8.

4 Askie LM, Darlow BA, Finer N, et al. Association between oxygen saturation targeting and death or disability in extremely preterm infants in the neonatal oxygenation prospective meta-analysis CollaborationAssociation between oxygen saturation targeting and death or disability in extremely preterm InfantsAssociation between oxygen saturation targeting and death or disability in extremely preterm infants. JAMA 2018:319:2190-201.

5 Gilbert C, Fielder A, Gordillo L, et al. Characteristics of infants with severe retinopathy of prematurity in countries with low, moderate, and high levels of development: implications for screening programs. Pediatrics 2005;115:e518-25.

6 Gilbert C. Retinopathy of prematurity: a global perspective of the epidemics, population of babies at risk and implications for control. Early Hum Dev 2008;84:77-82.

7 Blencowe H, Lawn JE, Vazquez T, et al. Preterm-associated visual impairment and estimates of retinopathy of prematurity at regional and global levels for 2010. Pediatr Res 2013;74:35-49.

8 WHO. Oxygen therapy for children: a manual for health workers. Geneva, Switzerland: World Health Organization, 2016

9 Hagadorn Jl, Furey AM, Nghiem T-H, et al. Achieved versus intended pulse oximeter saturation in infants born less than 28 weeks' gestation: the AVIOx study. Pediatrics 2006;118:1574-82.

10 Laptook AR, Salhab W, Allen J, et al. Pulse oximetry in very low birth weight infants: can oxygen saturation be maintained in the desired range? J Perinatol 2006;26:337-41

11 van Zanten HA, Tan RNGB, van den Hoogen A, et al. Compliance in oxygen saturation targeting in preterm infants: a systematic review. Eur J Pediatr 2015;174:1561-72.

12 Herbert LJ, Wilson IH. Pulse oximetry in low-resource settings. Breathe 2012;9:90-8.

13 Graham H, Ayede A, Bakare A, et al. Oxygen for children and newborns in nontertiary hospitals in south-west Nigeria: a needs assessment. Afr J Med med Sci 2016:45:31-49.

14 Wandi F, Peel D, Duke T. Hypoxaemia among children in rural hospitals in Papua New Guinea: epidemiology and resource availability - a study to support a national oxygen programme. Ann Trop Paediatr 2006;26:277-84.

15 McCollum ED, Bjornstad E, Preidis GA, et al. Multicenter study of hypoxemia prevalence and quality of oxygen treatment for hospitalized Malawian children. Trans R Soc Trop Med Hyg 2013;107:285-92. 
16 Graham HR, Bakare AA, Gray A, et al. Adoption of paediatric and neonatal pulse oximetry by 12 hospitals in Nigeria: a mixed-methods realist evaluation. BMJ Glob Health 2018;3:e000812.

17 Graham HR, Ayede Al, Bakare AA, Oyewole OB, et al. Improving oxygen therapy for children and neonates in secondary hospitals in Nigeria: study protocol for a steppedwedge cluster randomised trial. Trials 2017;18:502.

18 Subhi R, Adamson M, Campbell H, et al. The prevalence of hypoxaemia among ill children in developing countries: a systematic review. Lancet Infect Dis 2009;9:219-27.

19 Hartnett ME, Penn JS. Mechanisms and management of retinopathy of prematurity. N Engl J Med 2012;367:2515-26.

20 Pal AK, Sur S, Gupta AK. Incidence of retinopathy of prematurity and its association with oxygen therapy in preterm low birth weight babies. J Nepal Paediatr Soc 2016;35:247-52.

21 Wallace DK, Veness-Meehan KA, Miller WC. Incidence of severe retinopathy of prematurity before and after a modest reduction in target oxygen saturation levels. J Aapos 2007;11:170-4.

22 Clucas L, Doyle LW, Dawson J, et al. Compliance with alarm limits for pulse oximetry in very preterm infants. Pediatrics 2007;119:1056-60.

23 Sola A, Golombek SG, Montes Bueno MT, et al. Safe oxygen saturation targeting and monitoring in preterm infants: can we avoid hypoxia and hyperoxia? Acta Paediatr 2014; 103:1009-18.

24 Dubowitz G, Breyer K, Lipnick M, et al. Accuracy of the Lifebox pulse oximeter during hypoxia in healthy volunteers. Anaesthesia 2013;68:1220-3.

25 Enright A, Merry A, Walker I, et al. Lifebox: a global patient safety initiative. A A Case Rep 2016:6:366-9.

26 King CMT, Sessions K, et al. Performance of a novel re-usable paediatric pulse oximeter probe. Pediatr Pulmonolln press.
27 Sink DW, Hope SAE, Hagadorn Jl. Nurse:patient ratio and achievement of oxygen saturation goals in premature infants. Arch Dis Child Fetal Neonatal Ed 2011;96:F93-F8.

28 van der Eijk AC, Dankelman J, Schutte S, et al. An observational study to quantify manual adjustments of the inspired oxygen fraction in extremely low birth weight infants. Acta Paediatr 2012;101:e97-104.

29 Morgan MC, Maina B, Waiyego M, et al. Pulse oximetry values of neonates admitted for care and receiving routine oxygen therapy at a resource-limited hospital in Kenya. J Paediatr Child Health 2018;54:260-6.

30 Di Fiore JM, Bloom JN, Orge F, et al. A higher incidence of intermittent hypoxemic episodes is associated with severe retinopathy of prematurity. $J$ Pediatr 2010;157:69-73.

31 WHO. Children: reducing mortality Geneva, Switzerland: World Health organization, 2016. Available: http://www.who.int/mediacentre/factsheets/fs178/ en/

32 Gilbert C, Rahi J, Eckstein M, et al. Retinopathy of prematurity in middle-income countries. The Lancet 1997:350:12-14.

33 Adio AO, Ugwu RO, Nwokocha CG, et al. Retinopathy of prematurity in Port Harcourt, Nigeria. ISRN Ophthalmology 2014;2014:1-6.

34 Plottier GK, Wheeler KI, Ali SKM, et al. Clinical evaluation of a novel adaptive algorithm for automated control of oxygen therapy in preterm infants on non-invasive respiratory support. Arch Dis Child Fetal Neonatal Ed 2017;102:F37-43.

35 Van Zanten HA, Kuypers KLAM, Stenson BJ, et al. The effect of implementing an automated oxygen control on oxygen saturation in preterm infants. Arch Dis Child Fetal Neonatal Ed 2017;102:F395-F9.

36 Mitra S, Singh B, El-Naggar W, et al. Automated versus manual control of inspired oxygen to target oxygen saturation in preterm infants: a systematic review and metaanalysis. Journal of Perinatology 2018;38:351-60. 